Research, Society and Development, v. 9, n. 11, e199119560, 2020

(CC BY 4.0) | ISSN 2525-3409 | DOI: http://dx.doi.org/10.33448/rsd-v9i11.9560

\title{
Lei de improbidade administrativa: uma revisão sistemática
}

Administrative improbity law: a systematic review

Ley administrativa de improbidad: una revisión sistemática

Recebido: 23/10/2020 | Revisado: 25/10/2020 | Aceito: 28/10/2020 | Publicado: 02/11/2020

\author{
Juliana Maria Fernandes Correia de Araújo \\ ORCID: https://orcid.org/0000-0002-7972-142X
}

Universidade Federal Rural de Pernambuco, Brasil

E-mail: julianafca@live.com

Ionete Cavalcanti de Moraes

ORCID: https://orcid.org/0000-0003-0621-618X

Universidade Federal Rural de Pernambuco, Brasil

E-mail: ionetemoraes@gmail.com

\section{Resumo}

A Lei de Improbidade Administrativa representa um marco na legislação brasileira no que concerne o combate à corrupção. Ao estabelecer limites no rol de atuação dos agentes públicos, a Lei sanciona condutas atentatórias ao erário e aos princípios da Administração Pública. Porém, após duas décadas de vigência, a aplicação dessa norma ainda permeia diálogos no campo da ciência jurídica. Dessa forma, esse artigo tem o objetivo de realizar uma revisão sistemática de literatura com o intuito de investigar a produção científica de artigos que versem sobre essa matéria. Entende-se que essa revisão permitirá identificar as lacunas existentes, orientando assim, futuros estudos sobre o tema. A base de dados escolhida foi o Periódico CAPES onde foram selecionados 11 estudos. Ao analisar os resultados pode-se constatar um grande lapso temporal entre a vigência da lei e a publicação dos artigos pesquisados. Isto demonstra que, apesar de 28 anos de vigência, a Lei de Improbidade continua sendo alvo de discussão. Observou-se a inevitável associação das pesquisas a condutas corruptas e a improbidade administrativa nas condutas ofensivas ao meio ambiente. Outro ponto de destaque é a utilização da metodologia qualitativa, pela maioria dos pesquisadores.

Palavras-chave: Improbidade administrativa; Corrupção; Administração pública. 


\section{Abstract}

The Administrative Improbity Law represents a milestone in Brazilian legislation with regard to combating corruption. By establishing limits on the role of public agents, a Law sanctions conduct that undermines the treasury and the principles of Public Administration. However, after two decades in force, the application of this standard still permeates dialogues in the field of legal science. Thus, this article aims to conduct a systematic literature review in order to investigate the scientific production of articles dealing with this matter. It is understood that this review will allow the identification of existing gaps, thus guiding future studies on the topic. The database chosen was the CAPES Periodical where 11 studies were selected. When analyzing the results, it is possible to notice a large time lag between the law and the publication of the researched articles. This shows that, despite 28 years in force, the Improbity Law continues to be the subject of discussion. There was an inevitable association between research and corrupt conduct and administrative improbity in conduct offensive to the environment. Another highlight is the use of qualitative methodology, by most researchers.

Keywords: Administrative improbity; Corruption; Public administration.

\section{Resumen}

La Ley de Improbidad Administrativa representa un hito en la legislación brasileña en materia de lucha contra la corrupción. Al establecer límites al rol de los agentes públicos, la Ley sanciona conductas que atenten contra la tesorería y los principios de la Administración Pública. Sin embargo, después de dos décadas de vigencia, la aplicación de esta norma aún impregna los diálogos en el campo de las ciencias jurídicas. Por lo tanto, este artículo tiene como objetivo realizar una revisión sistemática de la literatura con el fin de investigar la producción científica de los artículos que abordan este asunto. Se entiende que esta revisión permitirá identificar las brechas existentes, orientando así futuros estudios sobre el tema. La base de datos elegida fue la Revista CAPES donde se seleccionaron 11 estudios. Al analizar los resultados, es posible notar un gran desfase entre la ley y la publicación de los artículos investigados. Esto muestra que, a pesar de 28 años de vigencia, la Ley de Improbidad continúa siendo objeto de discusión. Había una asociación inevitable entre la investigación y la conducta corrupta y la improbidad administrativa en la conducta ofensiva para el medio ambiente. Otro punto a destacar es el uso de metodología cualitativa, por la mayoría de investigadores.

Palabras clave: Improbidad administrativa; Corrupción; Administración pública. 


\section{Introdução}

A corrupção constitui um antigo fenômeno social que tem permeado a história política do Brasil desde os tempos da colonização (Araújo, 2011). Nesse sentido, a corrupção se caracteriza como um fenômeno que permeia diversas instituições, envolvendo condutas reiteradas não só individuais como coletivamente, com alto grau de institucionalização, racionalidade e invisibilidade (Dobrowolski, 2018). Como consequência, o funcionamento do Estado e sua própria legitimidade enquanto regime democrático se tornam palpáveis de questionamento.

Nesse contexto, a agenda contemporânea de combate a corrupção tem cada vez mais urgência, tanto no campo social quanto no campo do direito, de adotar mecanismos efetivos de prevenção e punição das condutas ímprobas. Ainda, práticas de corrupção, que têm como consequência o desvio de determinada função pública, adquirem, no Brasil, grandes dimensões a partir das últimas décadas (Costa, Cunha, Bezerra, Oliveira, Vale Júnior \& Severiano Junior, 2020). Nesse sentido, corrupção e ineficiência surgem como fenômenos endêmicos do sistema político (Boukouras \& Koufopoulos, 2008).

Para evidenciar o contexto em que a administração pública se encontra, é importante diferenciar três conceitos: governo, estado e administração pública. Segundo Paludo (2017), o governo traduz-se no modelo pelo qual o Estado é administrado, ou seja, como são definidos os objetivos e as diretrizes de sua atuação, fixadas as políticas públicas e tomadas as decisões de caráter político administrativo. Rua (2014), nesse mesmo sentido, define governo como o núcleo decisório do Estado. Já Meirelles (2012), atribui três sentidos para governo, o sentido formal cuja composição contém um conjunto de poderes e órgãos constitucionais, o sentido material, caracterizado por um complexo de funções estatais, e o sentido operacional, formalizado na condução política dos negócios públicos.

O Estado é caracterizado como o detentor do poder soberano, isso porque, ele exerce o seu poder através do governo, sendo esse o instrumento para o Estado atuar na consecução de suas finalidades (Paludo 2017). O Estado, conforme salientado por Berringer (2017), é uma instituição e uma associação de indivíduos dotada de legitimidade para o uso da força. $\mathrm{Na}$ realidade, o Estado é uma organização compulsória da sociedade (Morgenthau, 2003).

Sob a ótica de uma perspectiva histórica da Administração Pública, há diversas correntes teóricas calcadas por diferentes bases epistemológicas (Abreu, Helou \& Fialho, 2013). A despeito dos embates teóricos, a ideia central de administração é a ação corretamente calculada para realizar determinados objetivos desejados (Granjeiro, 2006). 
A realização desses objetivos deve ser executada de acordo com os deveres gerais impostos aos agentes públicos fundamentados na probidade, ou seja, na qualidade de ser probo, íntegro e honesto. O conceito de probidade, nesse caso, está intimamente relacionado ao de moralidade administrativa, que prescreve o dever do agente de servir à Administração Pública com honestidade, exercendo suas atribuições no intuito de alcançar o interesse público, sem tirar proveito pessoal dos poderes inerentes a eles (Di Pietro, 2018).

Nessa conjuntura, a improbidade administrativa é tratada como sinônimo jurídico de corrupção e malversação administrativa (Oliveira \& Nascimento, 2015). Nesse sentido, improbidade pode ser definida como uma forma de corrupção que se completa com o exercício da ilegalidade, ao atentar contra ordenamento jurídico e corromper a função pública. Para Cancellier e Orssatto (2011), improbidade é resultado de todo ato praticado por agente contrário à moral, à lei e aos bons costumes, tendo como característica a falta de honradez e de retidão de conduta perante o Estado.

Os atos de improbidade não são apenas um reflexo da má gestão dos recursos públicos, são atos, sobretudo, que atentam contra os direitos da pessoa humana e inviabilizam a execução material dos direitos prestacionais devidos pelo Estado (Araújo, 2011). Portanto, esses atos são contrários aos preceitos fundamentais da Constituição e aos direitos e garantias individuais e coletivos preconizados nela.

A inequívoca preocupação constitucional com a moralidade da Administração Pública se tornou palpável na Constituição Federal de 1988, em seu Artigo 37, o qual prevê, para os atos de improbidade administrativa, a suspensão dos direitos políticos, a perda da função pública, a indisponibilidade dos bens e o ressarcimento ao erário. Assim, ao limitar o exercício do Poder Público, a Constituição objetivou não só garantir o respeito aos princípios inerentes à administração pública: legalidade, impessoalidade, moralidade e eficiência, como também defender um microssistema normativo anticorrupção (Dobrowolski, 2018).

Segundo Souza e Fidalgo (2018), essa inclusão formal de normas constitucionais voltadas à Administração Pública é uma das facetas do fenômeno da constitucionalização do Direito que consiste na expansão do conteúdo material e axiológico das normas constitucionais para o ordenamento jurídico. Em decorrência desse fenômeno, os valores, a finalidade pública e o comportamento probo contemplados no conjunto de princípios e normas constitucionais passaram a condicionar a validade e o sentido tanto da própria legislação quanto do papel do agente público (Barroso, 2004).

O reconhecimento da força normativa dos princípios é abarcado justamente no contexto de responsabilização do agente público pela sua inobservância. Nesse sentido, Di 
Pietro (2018) ensina que princípios são proposições básicas, fundamentais, típicas, que condicionam estruturas subsequentes. Em matéria de improbidade, é importante destacar o princípio da moralidade e seus vieses. Isso porque, de acordo com Furtado (2007), não se exige o mero cumprimento é lei, exige-se muito mais, ou seja, uma conduta que seja impecável, ilibada e exemplar. O princípio da moralidade é, para esse autor, um dos princípios de mais difícil definição, já que sua compreensão se dá por meio da descrição de condutas que lhe sejam contrárias.

Com efeito, a responsabilização dos agentes públicos, servidores ou não, que pratiquem atos de improbidade contra a Administração direta, indireta ou fundacional é feita pela Lei de Improbidade Administrativa. Essa responsabilização configura o princípio da responsabilidade estatal e representa uma das mais importantes decorrências jurídicas do Estado Democrático de Direito. Dessa forma, o poder dos agentes públicos é legitimado pela lei e a margem de discricionariedade de sua atuação é delimitada pelo princípio da legalidade. Por isso, o agente público só deve fazer aquilo que a lei permite e ao fazer, tem o dever de prestar contas, tornando, assim, legítima a ação do próprio Estado.

A Lei de Improbidade administrativa, ao conceituar quais são os atos de improbidade, simbolizou um marco na legislação brasileira por representar um significativo meio de combate à corrupção. Os atos de improbidade decorrem de três situações, qual sejam, enriquecimento ilícito, prejuízo ao erário ou contra os princípios da administração pública. Assim, a promulgação da Lei de Improbidade Administrativa garantiu uma maior segurança jurídica na proteção dos bens e valores públicos e consolidou uma nova forma de controle da Administração Pública.

Após duas décadas de vigência, a lei de improbidade administrativa ainda permeia diálogos no ramo da ciência jurídica. Entre os debates, por exemplo, ainda é presente a dúvida sobre a aplicação da lei de improbidade aos agentes políticos (Cancellier \& Orssatto, 2011; Santos \& Herman, 2015). Além disso, também há controvérsia acerca da responsabilização do administrador público que causar danos ao meio ambiente (Colombo \& Freitas, 2016; Nascimento \& Oliveira, 2015) e sobre o grau de efetividade processual da Lei nos casos envolvendo corrupção (Arantes \& Moreira, 2019).

Diante dessas problemáticas, surgem dúvidas acerca da efetividade da lei de improbidade no combate aos atos ímprobos, da possibilidade de mudanças na conduta dos agentes públicos após a vigência da lei e da criação de um mecanismo eficaz de prevenção à corrupção. Por isso, é importante pesquisar sobre a improbidade e identificar sua aplicação diante das nuances na realidade jurídico-social. 
Considerando as reflexões acima, este estudo buscou a resposta da seguinte questão: Como se encontra a produção científica nacional sobre a Lei de Improbidade Administrativa (Lei n. 8429, 1992)? Apesar de estudos sobre o tema, pouco se sabe sobre as nuances dessa Lei. Desse modo, entende-se que realizar uma revisão sistemática permitirá a identificação de estudos relevantes sobre o tema, com base em critérios de seleção definidos. Isso permitirá identificar as lacunas existentes, orientando assim, futuros estudos sobre o tema.

Desse modo, ao analisar o que tem sido publicado em artigos sobre essa temática, tendo como orientação os anos de 1992 até março de 2020, esse artigo tem como objetivo geral investigar como se encontra a produção científica nacional sobre a Lei n. 8429 (1992). Como objetivos específicos, o presente estudo tem o intuito de identificar: quais áreas produziram sobre o tema; quais revistas foram publicados os artigos; qual o viés desses estudos e suas metodologias.

\section{Metodologia}

Esse estudo tem uma abordagem qualitativa de natureza descritiva, pois objetivou descrever um fenômeno a partir de estudos publicados em artigos (Severino, 2007). Na pesquisa qualitativa, o pesquisador reduz a distância entre a teoria e os dados, entre o contexto e a ação, compreendendo os fenômenos para sua descrição e interpretação (Teixeira, 2011). Dessa forma, essa abordagem proporciona um aprofundamento da pesquisa, através da ampliação do contato direto com a situação estudada (Gil, 1999).

Quanto à natureza, essa pesquisa se caracteriza como um estudo descritivo, isso porque, segundo Gil (1999), pesquisas descritivas têm como objetivo a descrição das características de um determinado fenômeno, nesse caso, a Lei de Improbidade Administrativa. Dessa forma, a pesquisa descritiva expõe as características de determinada população ou fenômeno, estabelecendo variáveis e definindo sua natureza (Vergara, 2000).

Optou-se por realizar uma Revisão Sistemática da Literatura - RSL. Esse tipo de pesquisa, como explica Castro (2001), se trata de uma revisão planejada. O objetivo é responder uma pergunta específica de pesquisa, utilizando métodos explícitos e sistemáticos de pesquisa para identificar, selecionar e avaliar criticamente estudos, relacionados ao objetivo específico determinados pelo pesquisador. Além disso, Morandi e Camargo (2015, p. 141), enfatizam que a "RSL é uma etapa fundamental da condução de pesquisas científicas, especialmente de pesquisas realizadas sob o paradigma da Design Science”. Desse modo, justifica-se sua aplicação nessa investigação uma vez que se busca investigar como se 
encontra a produção científica nacional sobre a Lei de Improbidade Administrativa (Lei n. 8429, 1992).

A revisão sistemática é um modelo de pesquisa que utiliza como fonte de dados a literatura sobre o tema a ser pesquisado. Esses tipos de revisão são úteis para concatenar informações de um conjunto de pesquisas, que, apesar de serem realizadas separadamente, quando unidas em uma revisão, podem apresentar resultados conflitantes e/ou coincidentes (Sampaio \& Mancini, 2007).

Além disso, a revisão sistemática vai auxiliar na orientação para futuras pesquisas. Uma vez que disponibiliza um resumo das evidências relacionadas a uma estratégia de intervenção específica (Sampaio \& Mancini, 2007). Por isso, esse estudo visa agrupar as pesquisas sobre a Lei de Improbidade para que próximos trabalhos tenham acesso compilado ao que já foi produzido e às lacunas existentes nessas produções. Pires, Menegassi e Tatoo (2016), explicam que esse tipo de metodologia investigar todo material publicado sobre um determinado tema em um período estipulado pelo pesquisador, o que é realizado nesse estudo.

$\mathrm{Na}$ produção desta revisão, foram utilizadas as etapas da revisão sistemática, apresentadas no Quadro 1, adaptada de Sampaio e Mancini (2007). A primeira etapa correspondente ao problema de pesquisa, que neste estudo foi definida pela questão: Como se encontra a produção científica nacional sobre a Lei de Improbidade Administrativa (Lei n. $8429,1992)$ ? A etapa seguinte foi efetuar um protocolo de investigação e fazer seu registro. A base de dados escolhida foi o Portal de Periódico CAPES. Esse portal foi escolhido por ser uma base de dados capaz de contemplar um extenso quantitativo de conteúdos, uma vez que tem como característica o fato de ser uma biblioteca virtual, reunindo e disponibilizando um acervo de mais de 45 mil títulos e ao menos 130 bases referenciais.

Paralelamente, foram desenvolvidas as palavras-chave ou string de busca, para colocar na respectiva base e, assim, observar os resultados apresentados. As palavras-chave escolhidas foram "lei de improbidade administrativa" e "improbidade administrativa". Entretanto, optou-se por usar apenas lei de improbidade, pois a palavra-chave improbidade administrativa não resultou em artigos acerca, especificamente, da Lei de Improbidade. Além disso, o marco temporal foi representado pelo período desde a vigência da lei, a partir de 1992, até o mês de maio de 2020 (Quadro1).

A etapa seguinte foi a realização das buscas na base de dados selecionada, por meio, dos termos definidos. Após essa busca, iniciou-se o processo de seleção dos artigos, do qual foram retirados os artigos em duplicidade e lidos, inicialmente, os títulos e resumos, conforme demonstra o Quadro 1. A seleção foi realizada na própria base de dados utilizando os 
seguintes critérios de inclusão e exclusão: inclusão - artigos que apresentavam a lei no seu resumo ou no título e estavam disponíveis por completo; exclusão - artigos que não abordavam a lei no seu resumo e, por isso, tinham outro objeto de estudo.

Essa primeira leitura proporcionou a exclusão de artigos que não abordavam a lei, após essa filtragem, foram lidos os artigos por completo. A leitura completa dos artigos foi importante para a seleção final, através da qual foram excluídos os que não tratavam sobre Lei de Improbidade ou apenas a citavam, sem maiores explicações. Feita a leitura, a etapa seguinte foi observar a qualidade dos artigos selecionados. O critério de avaliação da qualidade foi feito por meio do Qualis da revista em que cada artigo foi publicado. Assim, os artigos selecionados tinham que ser publicados em revistas na área de administração avaliadas com Qualis igual ou superior à B2. Como consequência dessa seleção 11 artigos foram selecionados para a análise dos dados. Por fim, foi realizado a síntese dos dados e apresentado nos resultados do estudo.

Quadro 1. Etapas da revisão sistemática.

\begin{tabular}{|c|c|}
\hline ETAPAS & CRITÉRIOS \\
\hline Questão de investigação & $\begin{array}{l}\text { Como se encontra a produção científica } \\
\text { nacional sobre a Lei de Improbidade } \\
\text { Administrativa (Lei n. } 8429,1992) ?\end{array}$ \\
\hline Protocolo de investigação & $\begin{array}{l}\text { - Palavra-chave: lei de improbidade } \\
\text { administrativa; } \\
\text { - Tipo de estudo a ser selecionado: artigo; } \\
\text { - Idiomas dos estudos: português; } \\
\text { - Bases de dados: Portal CAPES; } \\
\text { - Critérios de seleção (inclusão e exclusão): } \\
\text { estudos disponíveis de forma gratuita na } \\
\text { íntegra, estudos publicados a partir de 1992, } \\
\text { até o mês de maio de } 2020 \text {. }\end{array}$ \\
\hline Estratégia de pesquisa & $\begin{array}{l}\text { A estratégia adotada contempla buscas na base } \\
\text { de dados Portal CAPES com os termos: "lei de } \\
\text { improbidade administrativa" }\end{array}$ \\
\hline
\end{tabular}




\begin{tabular}{|l|l|}
\hline & $\begin{array}{l}1^{a} \text { Leitura dos títulos e resumos } \\
\text {-Exclusão dos artigos que não abordavam a lei } \\
\text { no seu resumo e, por isso, tinham outro objeto } \\
\text { de estudo e que não estavam completos. } \\
\text { - Inclusão dos artigos que apresentavam a lei } \\
\text { no seu resumo ou no título estavam } \\
\text { disponíveis por completo } \\
2^{\text {a }} \text { Leitura completa dos artigos } \\
\text { - Exclusão dos artigos que não tratavam sobre } \\
\text { a Lei e dos que apenas a citavam, sem maiores } \\
\text { explicações. } \\
\text { Inclusão - artigos que falavam sobre a lei }\end{array}$ \\
\hline Artigos & $\begin{array}{l}\text { Verificação do Qualis revistas } \\
\text { artigos }\end{array}$ \\
\hline \multirow{2}{*}{ Inclusão apenas daquelas acima de B2 } \\
Apresentação dos dados
\end{tabular}

Fonte: Elaborado pelas autoras com base em Sampaio e Mancini (2007).

A análise dos dados foi feita por meio da análise de conteúdo. O objetivo deste tipo de análise está em identificar o que está sendo dito a respeito de determinado tema (BARDIN, 2006). A escolha desse tipo de ferramenta ocorreu em virtude de a técnica funcionar seguindo procedimentos sistemáticos e objetivos de descrição do conteúdo das entrevistas. Desse modo, para o desenvolvimento da análise cada objetivo específico foi escolhido como um tema-eixo. Assim, foi construído uma arquitetura de etapas: Escolha do tema-eixo (objetivos específicos) >>Leitura de todos os artigos selecionados $>>$ Registro dos núcleos de sentido que respondem aos objetivos >> Releitura dos artigos >>Seleção e recorte dos núcleos de sentido mais significativos >> Inferência dos resultados para responder o objetivo específicos. 


\section{Resultados e Discussão}

\subsection{Produção científica nacional sobre a lei de improbidade e seus vieses}

De acordo com os dados coletados, foram selecionados 11 artigos para uma análise mais profunda sobre o tema, como observado no Quadro 2. Desses artigos 6 são Qualis A e 5 são Qualis B. O mais antigo foi publicado em 2011 e o mais recente em 2018. Feito isso, para melhor visualização dos resultados, foram destacados os seguintes pontos: título; autores; ano e o respectivo Qualis.

Quadro 2. Artigos selecionados para a revisão sistemática.

\begin{tabular}{|c|c|c|c|c|}
\hline $\begin{array}{l}\text { Linha de } \\
\text { pesquisa }\end{array}$ & Título & Autores & Ano & Qualis \\
\hline \multirow{3}{*}{$\begin{array}{l}\text { Análise da Lei } \\
\text { de Improbidade }\end{array}$} & $\begin{array}{lr}\text { Lei } 8.429 / 1992: \text { uma } & \text { breve } \\
\text { análise sobre } & \text { suas } \\
\text { características } & \text { e } \\
\text { particularidades } & \end{array}$ & $\begin{array}{l}\text { Ribeiro, F., \& } \\
\text { Pinto, R. }\end{array}$ & 2018 & B1 \\
\hline & $\begin{array}{l}\text { A responsabilidade dos } \\
\text { agentes políticos pelos atos } \\
\text { de } \\
\text { administrativa }\end{array}$ & $\begin{array}{l}\text { Cancellier, L., } \\
\text { \& Orssatto, J. }\end{array}$ & 2011 & A1 \\
\hline & $\begin{array}{l}\text { A incidência do princípio da } \\
\text { insignificância nos atos de } \\
\text { improbidade administrativa }\end{array}$ & $\begin{array}{l}\text { Moraes, M., \& } \\
\text { Dias, P. }\end{array}$ & 2016 & B1 \\
\hline \multirow{3}{*}{$\begin{array}{l}\text { Improbidade e } \\
\text { corrupção }\end{array}$} & $\begin{array}{l}\text { Corrupção: } \\
\text { perspectivas e a discussão } \\
\text { sobre o princípio do bis in } \\
\text { idem }\end{array}$ & $\begin{array}{l}\text { Fortini, C., \& } \\
\text { Shermam, A. }\end{array}$ & 2018 & A1 \\
\hline & $\begin{array}{l}\text { Democracia, instituições de } \\
\text { controle e justiça sob a ótica } \\
\text { do pluralismo estatal }\end{array}$ & $\begin{array}{l}\text { Arantes, R., \& } \\
\text { Moreira, T. }\end{array}$ & 2019 & A2 \\
\hline & $\begin{array}{l}\text { Corrupção Burocrática } \mathrm{e} \\
\text { Empreendedorismo: } \quad \text { Uma }\end{array}$ & $\begin{array}{l}\text { Melo, } \quad \text { F., } \\
\text { Sampaio, L., \& }\end{array}$ & 2014 & A2 \\
\hline
\end{tabular}


Research, Society and Development, v. 9, n. 11, e199119560, 2020

(CC BY 4.0) | ISSN 2525-3409 | DOI: http://dx.doi.org/10.33448/rsd-v9i11.9560

\begin{tabular}{|c|c|c|c|c|}
\hline & $\begin{array}{l}\text { Análise Empírica dos Estados } \\
\text { Brasileiros }\end{array}$ & Oliveira, R. & & \\
\hline & $\begin{array}{l}\text { Corrupção e improbidades } \\
\text { nas contratações públicas que } \\
\text { prejudicam } \\
\text { desenvolvimento sustentável }\end{array}$ & $\begin{array}{l}\text { Nascimento, C., } \\
\text { \& Baracho, H. }\end{array}$ & 2017 & B1 \\
\hline \multirow{2}{*}{$\begin{array}{l}\text { Improbidade } \mathrm{e} \\
\text { meio ambiente }\end{array}$} & $\begin{array}{l}\text { Gestão democrática do meio } \\
\text { ambiente: uma análise crítica } \\
\text { dos mecanismos } \\
\text { participação popular nas } \\
\text { decisões ambientais à luz do } \\
\text { direito brasileiro }\end{array}$ & $\begin{array}{l}\text { Colombo, S., \& } \\
\text { Freitas, V. }\end{array}$ & 2016 & B1 \\
\hline & $\begin{array}{l}\text { A defesa do meio ambiente } \\
\text { na lei de improbidade } \\
\text { administrativa }\end{array}$ & $\begin{array}{l}\text { Nascimento, C., } \\
\text { \& Oliveira, F. }\end{array}$ & 2017 & B1 \\
\hline \multirow{2}{*}{$\begin{array}{l}\text { Ações de } \\
\text { Improbidade } \\
\text { Administrativa }\end{array}$} & $\begin{array}{l}\text { A administração pública na } \\
\text { tutela coletiva da moralidade } \\
\text { administrativa e do } \\
\text { patrimônio público: o papel } \\
\text { da advocacia }\end{array}$ & $\begin{array}{ll}\text { Mazzei, } & \text { M., } \\
\text { Lorenzi, } & \text { M, } \\
\text { Pazeto, } & \text { H., } \\
\text { Silveira, } & \text { S., }\end{array}$ & 2015 & A2 \\
\hline & $\begin{array}{l}\text { A Tensão entre Soberania e } \\
\text { Instituições de Controle na } \\
\text { Democracia Brasileira }\end{array}$ & $\begin{array}{l}\text { Avritzer, L., \& } \\
\text { Marona, M. }\end{array}$ & 2017 & A1 \\
\hline
\end{tabular}

Fonte: Elaborado pelas autoras (2020).

Após a sumarização dos estudos, foi possível perceber o grande lapso temporal entre a vigência da lei e a publicação dos artigos. Esses dados ressaltam que, apesar de 28 anos de vigência, a Lei de Improbidade continua sendo alvo de discussão. Por outro lado, é importante refletir sobre a falta de publicação de artigos nos anos 90 e começo dos anos 2000.

Essa revisão identificou que a produção dos artigos sobre improbidade administrativa está situada nas áreas de conhecimento do Direito e da Administração Pública. Isso porque, os artigos utilizaram tanto argumentos jurídicos, ao tratarem sobre a Lei em determinado aspecto, quanto estudos da Administração Pública, ao definirem agentes públicos e os 
princípios da Administração Pública que devem ser respeitados.

É importante ressaltar que a Lei de Improbidade Administrativa constitui um mecanismo de controle da administração pública (Arantes \& Moreira, 2019). Esse controle é constituído por um rol de mecanismos jurídicos, por meio dos quais a sociedade, o Estado e a própria Administração Pública exercem o poder de fiscalizar a função administrativa desempenhada pelos agentes públicos, com o intuito de garantir uma atuação conforme os princípios que lhe são impostos pelo ordenamento jurídico.

Em síntese, o estudo da improbidade administrativa está situado em uma linha tênue entre Direito e Administração, pois, à luz dos princípios que norteiam a conduta dos agentes na Administração Pública, a Lei tipifica as condutas que são ímprobas e reprováveis e, portanto, antijurídicas.

Quanto ao viés das pesquisas, cabe ressaltar a inevitável associação das pesquisas a condutas corruptas (Fortini \& Shermam, 2018; Melo, Sampaio \& Oliveira, 2014; Nascimento \& Baracho, 2017; Arantes \& Moreira, 2019). Além disso, dois artigos (Nascimento \& Oliveira, 2015; Nascimento \& Baracho, 2017) tiveram como objeto de estudo a improbidade administrativa nas condutas ofensivas ao meio ambiente, sobretudo, foram publicados na mesma revista.

O único autor (Nascimento, 2015; 2017) que publicou sobre improbidade mais de uma vez, segundo a base de dados dessa revisão, pesquisou sobre a constituição de uma conduta de improbidade diante de uma licença ambiental concedida de forma irregular e sobre improbidades nas licitações públicos com o intuito de prejudicar o desenvolvimento sustentável. Além disso, essa mesma autora publicou essa temática na mesma revista, o que torna perceptível tanto o perfil de publicação da revista, quanto do autor. Inclusive, o artigo sobre a óbice da corrupção em contratações públicas que envolvem o desenvolvimento sustentável demonstra que as linhas de pesquisa podem estar entrelaçadas, a partir da perspectiva tanto do pesquisador quanto do caso concreto.

O primeiro artigo, formulado por Ribeiro e Pinto (2018), que trata especificamente da Lei de Improbidade Administrativa foi publicado em 2018 e defende que a lei em questão ainda é o principal instrumento processual de busca pela moralidade administrativa e pelo combate à corrupção na administração pública. Porém, para os autores, a lei ainda é considerada vaga em seus conceitos. Esse argumento é corroborado pelo estudo de Cancellier e Orssatto (2011), pois os autores argumentam que há controvérsias quanto a aplicação da Lei de Improbidade aos agentes políticos, pelo fato deles também serem punidos pela Lei de Crimes de Responsabilidade. As leis entram em conflito, porque versam sobre os mesmos 
sujeitos ativos e delitos de ordem político-administrativa. $\mathrm{O}$ que diferencia essas duas normas é o fato de que a Lei de Improbidade é normal geral, se aplicando aos agentes públicos em geral, enquanto a Lei de Crimes de Responsabilidade é específica, opondo-se apenas aos agentes políticos.

Nesse contexto de responsabilização, Colombo e Freitas (2016) analisaram a gestão democrática do meio ambiente através de uma análise crítica dos mecanismos de participação popular nas decisões ambientais à luz do direito brasileiro. Para eles, o fato de a ação popular ainda ser pouco utilizada com a finalidade de proteger o meio ambiente, torna a Lei de Improbidade Administrativa mais efetiva na responsabilização do administrador público caso pratique uma conduta danosa ao meio ambiente. Porém, é imprescindível a participação popular na gestão pública, principalmente quanto às questões ambientais. Por isso, apesar da previsão legal de mecanismos de participação popular em matéria ambiental, ainda é preciso seu aperfeiçoamento.

Para Moraes e Dias (2016), apesar das controvérsias, a lei representa um verdadeiro código de conduta, o que a torna um instrumento salutar na defesa da moralidade administrativa. $\mathrm{O}$ estudo desses autores se concentrou na possibilidade de aplicação do princípio da insignificância nessa seara, questão controvertida tanto para a doutrina quanto para a jurisprudência.

Já a importância da pesquisa de Mazzei et al. (2015) decorre do estudo sobre o papel dos advogados públicos no desenvolvimento de uma rede de proteção à moralidade administrativa. Essa defesa é proporcionada por instrumentos como a lei de improbidade administrativa, pois a advocacia pública tem legitimidade ativa no ajuizamento da ação de improbidade.

Nessa mesma ótica, Arantes e Moreira (2019) destacam o protagonismo do Ministério Público, da Defensoria Pública e da Polícia Federal na esfera social e política. Porém, os autores salientam sobre o perigo de uma deterioração do sistema político acarretada pelos atos de luta contra a corrupção e a improbidade administrativa. Isso ocorreria através da soma de heterodoxas formas de aplicação punitiva, como a delação premiada, por exemplo. Esse contexto, aliado a judicialização de decisões políticas, tem gerado dúvidas acerca dos reais efeitos desse tipo de processo punitivo para a democracia brasileira.

O fato das conclusões das apurações realizadas pela administração pública ou pela polícia judiciária não condicionarem a atuação do Ministério Público faz com que o mesmo ostente uma enorme ingerência no amplo rol de estágios que organizam a fase de apuração das condutas que anuem o fenômeno da corrupção no Brasil (Avritzer \& Marona, 2017). 
Além da Lei de Improbidade Administrativa, há outros mecanismos legais de combate a corrupção, como a Lei Anticorrupção. O objetivo do artigo de Fortini e Shermam (2018) foi a realização de um estudo comparado entre esses dois dispositivos legais, diante da falta de sistematicidade no tratamento legislativo do combate à corrupção.

Diante da exposição geral sobre a matéria dos artigos desta revisão, é importante observar que, apesar de poucos trabalhos terem sido encontrados, há uma concentração de artigos em revistas de conceito A e B, o que demonstra que o tema tem sido publicado em revistas de prestígio e maior conceito acadêmico. Além disso, o cenário do Brasil, de uma forma geral, foi objeto de estudo de todos os artigos, que não desenvolveram um estudo regionalizado ou elencando unidades federativas diferentes. Dessa forma, os estudos se limitaram a compreensão nacional da Lei, abrindo margem para próximos estudos que tenham o objetivo de delimitar a aplicabilidade da improbidade administrativa em âmbito estadual ou municipal.

\subsection{Metodologia utilizada nos artigos}

Quanto ao aspecto metodológico, como é possível perceber no Quadro 3, o único artigo que utilizou a abordagem quantitativa, através de dados em painel como método de análise, foi o proposto por Melo et al. (2014). Segundo os autores, a utilização desse método foi justificada tanto pelo número limitado de observações, quanto pela possibilidade de incrementar o grau de liberdade da análise, elevando o número de observações. A abordagem quantitativa buscou estimar a relação entre empreendedorismo e corrupção burocrática, analisada para estados brasileiros. A principal hipótese trabalhada no artigo foi a corrupção burocrática afetar negativamente a atividade empreendedora brasileira. Quanto aos resultados encontrados pelos autores, houve uma correlação positiva entre corrupção e abertura de empresa, justificada pela alta regulamentação da atividade empreendedora, uma vez que agentes públicos poderiam ser corrompidos com o intuito de gerar celeridade em procedimentos de legalização de um negócio.

A corrupção burocrática tratada no artigo é definida como uma forma de influenciar a execução de leis, situação que é mais suscetível nos países em desenvolvimento, devido a menor capacidade de influência do público no processo legislativo. Essa conduta corruptiva está prevista na Lei de Improbidade Administrativa, seja pelo enriquecimento ilícito, pelo prejuízo ao erário ou pela ofensa aos princípios. Porém, a corrupção burocrática corrobora a ideia de que a prática governamental é vulnerável à ação corrupta dos indivíduos que, muitas 
vezes, atuam mediante grupos de interesse (Melo et al., 2014).

Quadro 3. Metodologia dos artigos selecionados.

\begin{tabular}{|l|l|}
\hline METODOLOGIA & ARTIGOS \\
\hline Quantitativa & \\
Método de análise: dados em painel & Melo et al.,2014) \\
\hline & $\begin{array}{l}\text { (Avritzer \& Marona, 2017) } \\
\text { (Cancellier \& Orssatto, 2011) } \\
\text { (Mazzei et al., 2015) } \\
\text { (Nascimento \& Oliveira, 2017) } \\
\text { (Nascimento \& Baracho, 2017) } \\
\text { (Arantes \& Moreira, 2019) } \\
\text { (Colombo \& Freitas, 2016) } \\
\text { (Fortini \& Shermam, 2018) } \\
\text { (Moraes \& Dias, 2016) } \\
\text { (Ribeiro \& Pinto, 2018) }\end{array}$ \\
\hline
\end{tabular}

Fonte: Elaborado pelas autoras (2020).

Ainda que tenha sido encontrado apenas um resultado que utilizou a metodologia quantitativa, é imprescindível ressaltar que a abordagem majoritária é a qualitativa, o que demonstra o interesse metodológico dos pesquisadores na área. Assim, pesquisas quantitativas que explorem de maneira profunda a Lei de Improbidade Administrativa ainda são escassas.

Uma das justificativas para a escolha da metodologia qualitativa é uma maior preocupação em compreender, de uma forma profunda, o mecanismo dos grupos sociais, em detrimento de representações numéricas (Ribeiro \& Pinto, 2018). As abordagens qualitativas, de um modo geral, utilizaram o tipo de pesquisa bibliográfica (Nascimento \& Baracho, 2017; Nascimento \& Oliveira, 2015). Nesse contexto, os resultados foram concluídos através de buscas utilizando o ordenamento jurídico que, por ser tão plural, se mostra um campo apto de pesquisa para a produção de outros artigos sobre o tema.

A revisão permitiu observar, portanto, que há pouco estudo sobre a Lei de Improbidade Administrativa e que há um certo padrão observado nos artigos, seja pela busca da metodologia qualitativa, seja pela associação ao estudo da corrupção em si. 


\section{Considerações Finais}

Essa pesquisa teve o intuito, através de uma revisão sistemática de literatura, de verificar a produção científica de artigos sobre a Lei de Improbidade Administrativa. Essa Lei é percebida no ordenamento jurídico brasileiro como um instrumento importante de consolidação de direito fundamentais e proteção do patrimônio público. É importante ressaltar que essa revisão sistemática não buscou esgotar a literatura, porque limitou sua pesquisa a artigos encontrados na base de dados objeto de estudo. Por isso, pesquisas futuras estão aptas a identificar um rol ampliado de estudos em dissertações, teses, livros, para que o objetivo seja mais abrangente.

É evidente a escassez de pesquisas sobre o tema, isso porque, o amplo espaço temporal elencado neste artigo foi capaz de encontrar apenas 11 artigos aptos ao estudo aprofundado do impacto da improbidade administrativa. Esse dado, por si só, é importante para instigar produções futuras, principalmente porque o assunto é interdisciplinar, podendo abarcar periódicos de Direito e Administração Pública. A busca pelo tema em áreas distintas contribui para uma compreensão global acerca da moralidade administrativa.

Constatou-se também que a Lei de Improbidade Administrativa tem conceitos vagos e que a conduta moral ainda é um desafio, tanto em sua identificação quanto nos termos da culpabilidade. Apesar de fortalecer a democracia e ser um marco na punibilidade de condutas ímprobas, a Lei ainda está longe de ser cumprida de forma plena. Sendo assim, é necessário um estudo sobre a causa dessas condutas, para que não haja apenas um mecanismo de repressão e, sim, de prevenção. A publicação da Lei ocorreu a mais de duas décadas e, ainda assim, condutas ímprobas ocorrem diariamente e grupos de interesse atuando de uma forma corrupta ainda assolam o Estado brasileiro. Existe mecanismo de repressão, mas não é efetivo como se propõe.

Por isso, essa revisão não é apenas composta por uma compilação de estudos, mas também por uma observação acerca das lacunas existentes no estudo da respectiva lei, fornecendo, portanto, oportunidade para futuros trabalho. Além disso, as revistas analisadas possuem uma ótima avaliação no Qualis o que representa um incentivo para os futuros pesquisadores. Não obstante, é importante destacar a limitação no trabalho na busca por artigos apenas em português, por isso, é sugerido para futuras pesquisas o estudo de periódicos internacionais, através da inclusão do inglês como idioma de pesquisa. Dito isso, será possível perceber o que a literatura internacional aponta em relação a Lei de Improbidade Administrativa. 
Por fim, entendeu-se que os dados sobre a efetividade da lei de improbidade ainda não foram estudados, apesar de serem extremamente importantes para a percepção jurídico-social do seu impacto. A Lei de Improbidade Administrativa permite uma administração pública transparente, esclarece quais as condutas reprimidas pelo Estado, por serem aptas a causarem prejuízo ao erário e, assim, a toda a sociedade. Por isso, o seu estudo tem caráter atemporal, pois a defesa da moralidade administrativa coaduna-se com a conduta que um Estado Democrático de Direito deve seguir.

\section{Referências}

Abreu, A. C. D., Helou, A. R. H. A., \& Fialho, F. A. P. (2013). Possibilidades epistemológicas para a ampliação da Teoria da Administração Pública: uma análise a partir do conceito do Novo Serviço Público. Cadernos EBAPE.BR, 11(4), 608-620.

Arantes, R. B., \& Moreira, T. M. Q. (2019). Democracia, instituições de controle e justiça sob a ótica do pluralismo estatal. Opinião Pública, 25(1), 97-135.

Araújo, M. O. (2011). Improbidade administrativa - da aplicação da Lei n. 8.429/1992 aos atos praticados por agentes políticos que respondem por crime de responsabilidade. Boletim Científico - Escola Superior do Ministério Público da União, 10(36), 223-284.

Avritzer, L., \& Marona, M. (2017). A Tensão entre Soberania e Instituições de Controle na Democracia Brasileira. Dados, 60(2), 359-393. doi: 10.1590/001152582017123.

Bardin, L. (2006). Análise de conteúdo. Lisboa: Edições 70.

Barroso, L. (2005). Neoconstitucionalismo e constitucionalização do Direito (O triunfo tardio do direito constitucional no Brasil). Revista De Direito Administrativo, 240, 1-42.

Berringer, T. (2017). O conceito de Estado para os estudos realistas das relações internacionais: uma análise sobre a obra A política entre as nações de Hans Morgenthau. Plural - Revista De Ciências Sociais, 24(2), 16-37. 
Boukouras, A., \& Koufopoulos, K. (2008). Political Competition, Ideology and Corruption. SSRN. dx.doi.org/10.2139/ssrn.1087777.

Cancellier, L. C. de O., \& Orssatto, J. H. C. (2011). A responsabilidade dos agentes políticos pelos atos de improbidade administrativa. Espaço Jurídico Journal of Law [EJJL], 12(2), 67 90.

Castro, A. A. (2001). Revisão Sistemática e Meta-Análise: Principais Desenhos. São Paulo. Recuperado em http://www.usinadepesquisa.com/metodologia/.

Colombo, S., \& Freitas, V. P. (2016). Gestão democrática do meio ambiente: uma análise crítica dos mecanismos de participação popular nas decisões ambientais à luz do direito brasileiro. Revista Thesis Juris, 5(1), 53-73.

Constituição da República Federativa do Brasil de 1988. (2018). [Coleção Saraiva de Legislação]. (55a ed.). São Paulo: Saraiva.

Costa, C. L. de O., Cunha, D. de O. da., Bezerra, L. F., Oliveira, F. L. de., Vale Júnior, J. S. do, \& Severiano Junior, E. (2020). The corruption in the brazilian public sector. Research, Society and Development, 9(10), e5939109056. doi.org/10.33448/rsd-v9i10.9056.

Di Pietro, M. S. Z. (2019). Direito Administrativo (32a ed). São Paulo: Forense.

Dobrowolski, S. C. (2018). Aspectos da aplicação adequada da lei de improbidade administrativa no atual enfrentamento à corrupção no brasil. Coletânea de artigos: avanços e desafios no combate à corrupção após 25 anos de vigência da Lei de Improbidade Administrativa, 142-193.

Fortini, C., \& Shermam, A. (2018). Corrupção: causas, perspectivas e a discussão sobre o princípio do bis in idem. Revista de Investigações Constitucionais, 5(2), 91-112.

Furtado, L. R. (2007). Curso de Direito Administrativo. Belo Horizonte: Fórum.

Gil, A. C. (1999). Métodos e técnicas de pesquisa social (5a ed). São Paulo: Atlas. 
Granjeiro, J. W. (2006). Administração Pública (12a ed). Brasília: Westcon.

Lei n. 8.429, de 02 de junho de 1992. (1992). Dispõe sobre as sanções aplicáveis aos agentes públicos nos casos de enriquecimento ilícito no exercício de mandato, cargo, emprego ou função na administração pública direta, indireta ou fundacional e dá outras providências. Diário Oficial da União. Brasília, DF.

Martin, D., Franklin, L., de Araújo, J., \& Castro, S. de. (2018). Lei De Acesso à Informação Brasileira A Partir De Uma Revisão Sistemática Da Literatura. Nucleus, 15(2), 163-176.

Mazzei, M. R., Lorenzi, M. T., Pazeto, H. P., Silveira, S. S., \& Geraige, Z., Neto. (2015). A administração pública na tutela coletiva da moralidade administrativa e do patrimônio público: o papel da advocacia pública. Revista de Administração Pública, 49(3), 699-717. doi: 10.1590/0034-7612130121.

Meirelles, H. L. (2012). Direito administrativo brasileiro (38a ed). São Paulo: Malheiros.

Melo, F. L. N. B., Sampaio, L. M. B., \& Oliveira, R. L. (2015). Corrupção Burocrática e Empreendedorismo: Uma Análise Empírica dos Estados Brasileiros. Revista de Administração Contemporânea, 19(3), 374-397. doi:10.1590/1982-7849rac20151611.

Moraes, M. A. P., \& Dias, P. M. de V. (2016). A incidência do princípio da insignificância nos atos de improbidade administrativa. Revista Controle, 14(1), 74-107.

Morandi, M. I. W. M., \& Camarco, L. F. R. (2015). Revisão sistemática da literatura. In: Dresch, A., Lacerda, D. P, \& Antunes, J. A. V., Jr. (2014). Design Science Research: Método de Pesquisa para Avanço da Ciência e Tecnologia, 141-175. Porto Alegre: Bookman. Recuperado em https://www.researchgate.net/publication/268172679_Design_Scienc e_Research_Metodo_de_Pesquisa_para_Avanco_da_Ciencia_e_Tecnologia.

MorGenthau, H. J. (2003). A política entre as nações - a luta pelo poder e pela paz. Brasília: UNB. 
Nascimento, C. M. L., \& Baracho, H. U. (2017). Corrupção e Improbidades nas contratações públicas que prejudicam o desenvolvimento sustentável. Revista Direito E Desenvolvimento, 6(12), 39 - 61.

Nascimento, C. M. L., \& Oliveira, F. P. M. (2017) A defesa do meio ambiente na lei de improbidade administrativa. Revista Direito e Desenvolvimento, 6(11), 11-31.

Paludo, A. V. (2017). Administração Pública (6a ed). Rio de Janeiro: Método.

Pires, L. A. D. B., Menegassi, C. H. M., \& Tatoo, L. (2016). Gestão do Conhecimento e Capital Humano: Uma Revisão Sistemática de Literatura. Revista Conbrad, 1(3), 204-220.

Ribeiro, F. da S., \& Pinto, R. S. (2015). Lei 8.429/1992: uma breve análise sobre suas características e particularidades. Revista Controle, 16(1), 141-170.

Rua, M. das G. (2014). Políticas Públicas (3a ed). Florianópolis: UFSC.

Sampaio, RF, \& Mancini, MC. (2007). Estudos de revisão sistemática: um guia para síntese criteriosa da evidência científica. Brazilian Journal of Physical Therapy,11(1), 8389. doi:10.1590/S1413-35552007000100013.

Santos, K., \& Hermany, R. (2015). Improbidade administrativa em casos julgados: posicionamento do TJRS na perspectiva municipalista e na condenatória pelo art. 11/lia. Revista Jovens Pesquisadores, 5(3).

Severino, A. J. (2007). Metodologia do trabalho científico (23a ed). São Paulo: Cortez.

Souza, J. M. de, \& Fidalgo, C. B. (2018). Legislação Administrativa para concursos (4a ed). Salvador: Juspodivm.

Teixeira, E. (2011). As três metodologias: acadêmica, da ciência e da pesquisa (8a ed). Petrópolis: Vozes.

Vergara, S. C. (2000). Projetos e relatórios de pesquisa em administração (3a ed). Rio de 
Janeiro: Atlas.

\section{Porcentagem de contribuição de cada autor no manuscrito}

Juliana Maria Fernandes Correia de Araújo - 50\%

Ionete Cavalcanti de Moraes $-50 \%$ 